Int. J. Dev. Biol. 52: 1051-1057 (2008)

doi: $10.1387 / \mathrm{ijdb} .082657 \mathrm{gs}$

\title{
Masculinization of XX Drosophila transgenic flies expressing the Ceratitis capitata Doublesex ${ }^{\mathrm{M}}$ isoform
}

\author{
GIUSEPPE SACCONE ${ }^{1, \#,}$ MARCO SALVEMINI ${ }^{1, \#, ~ A T T I L I O ~ P A N E ~}{ }^{1, \# \#}$ and LINO C. POLITO*,1,2 \\ ${ }^{1}$ Department of Biological Sciences, Genetics and Molecular Biology Section, University of Naples "Federico II" and \\ ${ }^{2}$ Institute of Genetics and Biophysics "A. Buzzati-Traverso", Naples, Italy
}

\begin{abstract}
The Doublesex (DSX) transcription factor regulates somatic sexual differentiation in Drosophila melanogaster. Female and male isoforms (DSX ${ }^{\mathrm{F}}$ and $\mathrm{DSX} \mathrm{M}^{\mathrm{M}}$ ) are produced due to sexspecific RNA splicing. Here we show that in the distantly related dipteran Ceratitis capitata, the $\mathrm{DSX}^{\mathrm{M}}$ male-specific isoform is conserved and able to induce masculinization of both somatic and germline tissues when ectopically expressed in XX Drosophila transgenic individuals.
\end{abstract}

KEY WORDS: Ceratitis, sex determination, DSX ${ }^{M}$ isoform

\section{Introduction}

In the genetic model system Drosophila melanogaster, the doublesex gene $(d s x)$ constitutes the terminal effector of the sex determination cascade in which the transformer (tra) and Sexlethal genes $(S X)$ are the main upstream regulators, and the XSEs (X-linked signalling elements) are the primary signal for sex determination (Erickson and Quintero, 2007). This sex determining regulatory cascade (XSE $>S X>$ tra $>d s x$ ) is based mainly on sex-specific alternative splicing: the protein product of a gene controls the sex-specific splicing of the pre-mRNA produced from a downstream gene in the genetic cascade (Nagoshi etal., 1988). $S x$ /plays the key role of maintaining female sex determination by a positive autoregulation (Cline, 1984). The transformer gene occupies an intermediate position in this hierarchy and is necessary for all aspects of female somatic sexual differentiation. The dsx gene regulates most aspects of somatic sexual differentiation and encodes two protein isoforms, DSX ${ }^{\mathrm{M}}$ and $\mathrm{DSX} \mathrm{F}^{\mathrm{F}}$, through sexspecific splicing of its primary transcript (Baker and Wolfner, 1988). The processing of the $d s x$ pre-mRNA in females requires the activity of the tragene and of transformer-2gene (tra-2), which encodes a non-sex-specific auxiliary factor with similarity to the SR family of RNA-binding proteins (Amrein et al., 1988, Hoshijima et al., 1991). The two DSX isoforms are responsible to promote male and female sexual development, respectively, by activating or repressing the transcription of a series of target genes in the two sexes (Burtis and Baker, 1989).

The doublesex gene is known to act in concert with other regulatory genes to control the development of the sexual dimorphic structures. For instance, in the Drosophilagenital disc, which gives rise to the terminalia and which is composed of two genital plus the anal primordia (Sanchez and Guerrero, 2001), dsx acts together with the homeotic gene $A b d o m i n a l-B(A b d-B)$ to determine which of the two genital primordia will develop and which will be repressed (Keisman and Baker, 2001, Sanchez and Guerrero, 2001). The bric-a-brac gene (bab) is involved in the sexually dimorphic pigmentation of the $5^{\text {th }}$ and $6^{\text {th }}$ abdominal tergites by integrating inputs from $d s x$ and $A b d-B$ (Kopp et al., 2000). Another integrated genetic input made up by $d s x$ and the homeotic gene Sex combs reduced ( $S C r$ ) has been invoked for sex-specific differentiation of the basitarsus of the prothoracic leg, developing sex combs in males (Jursnich and Burtis, 1993).

We have previously reported that similar to Drosophila, the Ceratitis capitata transformer homologue (Cctra) is required for the female-specific splicing of the Ceratitis dsx pre-mRNA (Graham et al., 2003, Pane et al., 2002). The evolutionary conservation of the tra $d s x$ genetic module was recently revealed also in other related Tephritidae as Bactrocera oleae (Lagos et al., 2007) and various Anastrephaspecies (Ruiz et al., 2007b). The molecular mechanism of $d s x$ regulation seems to be fairly conserved in insects since tra-2 homologues have been identified in Musca domestica (Burghardt et al., 2005) and in Ceratitis capitata (Salvemini et al., submitted) and are required in both these

Abbreviations used in this paper: DSX, doublesex; PRE, purine rich element.

\footnotetext{
*Address correspondence to: Lino C. Polito. Istituto di Genetica e Biofisica "A. Buzzati-Traverso" Via Pietro Castellino, 111,80100 - Napoli, Italy. Tel: +39-081-613-2353. Fax: +39-081-613-2706. e-mail: polito@igb.cnr.it
}

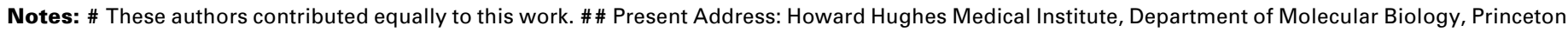
University, Princeton, NJ 08544, USA 
species for female-specific $d s x$ splicing.

This study reports the structure, the regulation and the evolutionary functional analysis of the Ceratitis dsxorthologue ( $C c d s x)$, performed by expressing the male-specific $C c d s x^{\mathrm{M}}$ isoform in transgenic Drosophila flies.

\section{Results}

To isolate the Ceratitis $d s x$ orthologue a radioactive probe was prepared from the Drosophilafemale-specific $d s x$ cDNA, which is highly conserved in other Tephritidae species, such as Bactrocera tryoni (Shearman and Frommer, 1998) and Bactrocera oleae (Lagos et al., 2005, Shearman and Frommer, 1998). The probe was used to screen two Ceratitis cDNA libraries (prepared respectively from female adults and dissected ovaries). Two clones, named F1 (1.1 Kb, from female adults) and Ov1 (1.6 Kb, from ovaries), were isolated and sequenced. Their sequences match a putative $d s x$ ORF truncated in the amino-terminus. RTPCR analysis on sexed adult flies confirmed that the two cDNA clones correspond to part of female-specific Ccdsx mRNAs. A PCR-based screening of a genomic medfly library led to the isolation of two additional non overlapping clones corresponding to the 5' and internal regions of the gene. RT-PCR analyses were performed to isolate the full-length $C c d s x$ ORFs encoding the $\mathrm{CcDSX}^{\mathrm{M}}$ and $\mathrm{CcDSX}^{\mathrm{F}}$ proteins. A 1.3 $\mathrm{Kb}$ male-specific cDNA fragment (M1) was amplified by using the BtdsxM reversed primer (designed on the Bactrocera oleae dsxmale-specific se-

Fig. 1. Comparison of the DSX predicted polypeptides in Dipteran species. Drosophila melanogaster (Dm) (Burtis and Baker, 1989), Ceratitis capitata (Cc) (this work), Anastrepha. obliqua (Ao) (Ruiz et al., 2007a, Ruiz et al., 2005), Bactrocera oleae (Bo) (Lagos et al., 2005), Bactrocera tryoni (Bt) (Shearman and Frommer, 1998) and Musca domestica (housefly) (Md) (Hediger et al., 2004). (A) Sequences common to both sexes; (B) female-specific sequences; (C) male-specific sequences. The DNA binding domain OD1 and the oligomerization domain OD2 are shaded in grey. Gaps were introduced in the alignments to maximize similarity.

\section{A Common region}

DM 1 MVSEE-NWN-SDTMSDSDMIDSKNDVCGGASS SSGSSIS PRT PPNCARCRNHGLKIT LKGHKRYCKF RYCTCE KCRLT ADRQR CC 1 MVSED-NWN-SDTMSDSDIHDSKADACGGASS SSGSSIS PRT PENCARCRNHGLKIT LKGHKRYCKF RYCTCE KCRLT ADRQR Ao 1 MVSED-NWN-SDTMSDSDMLDSKADVCGGASS SSGSSIS PRT PPNCARCRNHGLKIT LKGHKRYCKF RYCTCE KCRLT ADRQR BO 1 MVSED-NWN-SDTMSDS DMHDSKADVCGGAS S SGSSIS PRT PPNCARCRNHGLKIT LKGHKRYCKE RYCTCE KCRLT ADRQR Bt 1 MVSED-SWN-SDTIADSDMRDSKADVCGGASS SSGSSIS PRT PPNCARCRNHGLKIT LKGHKRYCKF RFCTCE KCRLT ADRQR Md 1 MVSEDSNWNS SDTMSDT DMHDSKADICGGASS SSGSSGT PRT KPNCARCRNHGLKIT LKGHKRYCKYRECNCE KCRLT ADRQR

Im VMALQTALRRAQAQDEQRALHMHEVP PAN PAATT LLSHHHHVAA.PAHVHAHHVHAHHAHGGHHS HHGHVLHHQQAAAAAAAA.PSA. CC VMALQT ALRRAQAQDEQRVLQI HEVP PGVHA. PAALLNHHH---------------- LHHHHHLNPNHHAT A.A.A.AAAAA-- Ao VMALQT ALRRAQAQDEQRVLQMHEVP PWHA. PTALLDHHH------------------LRHHH PLNQNHHAT A.AAAAAAAA--BO VMALQT ALRRAQAQDEQRVLQI HEVP PVWHG PTALLNHHH-------------------LHHHHHLNQNHHA.SAAAAAAAAA.--Bt VMALQT ALRRAQAQDEQRVLQI HEVP PVHHGPTALLNHHH---------------- LHHHHHLNQNHHA.SAAAAAAAAAA--Md VMALQTALRRAQQQDEARI LQMHEVP PWHP PTALLNAHHHHHH PL P------HHITQQLHHHPHHPHPHLVDVS AVAA.A.A.A.GV

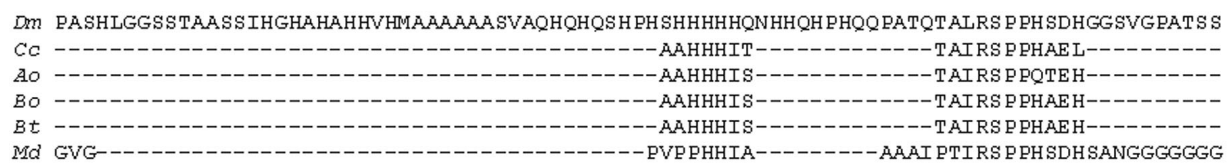

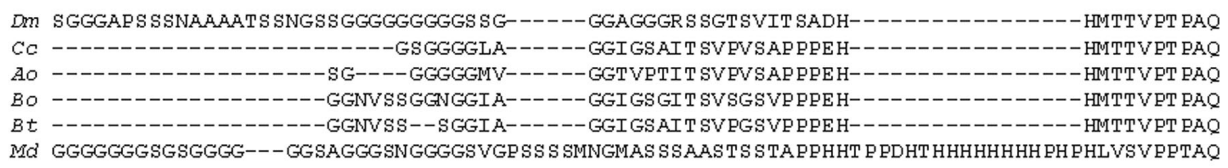

OD2

Dm SLEGSCDSS SPS PS ST SGA.AI L PI SVSVNRK----NGANVPLGQDVE LDYCQKLLE KFRY PWELM PLMYVILKDADANIEEASRR CC SLEGSSDT SP SS ST SG-AAL PI SVVGRKP S LH PNGVHMPLAQDVE LE HCQKLLE KFRY PW EMM PLMYVILKDAGADIE EA SRR AO SLEGSSDT S SP PS ST SG-AVL PI SVVGR KP PLH PNGVNI PLAQDVE LE HCOKLLE KFRY PW EMM PLMYVILKDAGADIE EA SRR BO SLEGSSDTS SPS PS ST SG-AVL PI SVVGRKPS LH PNGVNI PLAQDVF LE HCQKLLE KERY PW EMM PLMYVILKDAGADIEEASRR Bt SLEGSSDT S SP S PS ST SG-AVL PI SVVGRKP S LH PNGVNI PLAQDVE LE HCQKLLE KFRY PW EMM PLMYVILKDAGADIEEA SRR $M d$ SVDS SCDSS SP S PS ST SG-VAVPVLVPNRKPN PEQQQNGADM I DLI LDYCQKLIE KFGY PW EMM PLMYVILKDAGVDIDEA SKR
DM IEE 397
CC IEE 286
AO IEE 287
BO IEE 291
$B$ IEE 289
Md IEE 367

\section{B Female-specific region}

DM 398 GOYWNEYSROHNLNIYDGGELRNTTROCG 427 CC 287 GQHWNEYSRQHNLNIFDGGELRSTTRQCG 315 AO 288 GQHVVNEYSRQHNLNIYDGGELRSTTRQCG 317 BO 292 GQHWNEYSRQHNLNIYDGGELRSTTRQCG 321 Bt 290 GQHVVNEYSRQHNLNIYDGGELRSTTRQCG 319 Md 368 GQHWNEYSRQHNLNIYDGCELRCATRQCG 397

\section{Male-specific region}

Dm 398 --

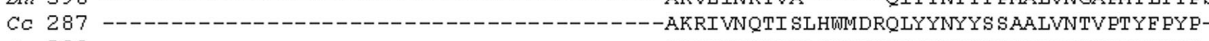
AO 288 -BO 292 -Bt 290 -Md 368 AIQLEKQYDSLIS--IYDGHEWRSKA.SLKRKAE SGARNAECDETTKRMRIEATEHLNQLTQTYYNYQRYA.LPPVYWGYPS

DM IEQG---RYG---AHETHL PLTQICPPTPE-PLALSR SPSS PSGPSAVHNQK PSRPGSSNGTVH SAASPTMVTTMATTS STPTLS CC IAIG---SNGLLTSQF SHLTAS-MRPPSPE-QPT LSRMPPSPS----_--KPSRPAS--_-_-_--ILSDTMSPPATAT SLT AO LAFG---TNGLLT SQF SHF TAS-IRP PSPE-LPALSRTP PS PS--------KLSRPAS-----------TLSETM SPVAATT SLK BO IAIG---SNGLLTSHE SHLTAS-IRP PSPE-QPT LSRTP PS PS--------KPSRPGS-----------ILSETM SPPAAAT SLT Bt IAIG---SNGLLTSHE SHLTAS-MRPPSPE-QPTLSRTPPSPS--------KPSRPGS-----------ILSETMSPPAAATNLP Md IQFGRAVWTEL PNPNE AALIP PHLAAT TPDGPQSLSRRS PS PF--------KNSRPSS----------SLGSE STTVT SLPTPG

DM RRQR SR AAT PT T PPPPPDAHS SNGAYHHGHHLVSSTAAT 549

CC S----A.AT------------

AO S----- SAT--------------------- A.AAAT 396

BO S----- SAT------------------A.A.T 400

Bt S----- SAT-----------------------AAAAT 398

Md VLAA.AA_A.AA----- 
A

\section{D. melanogaster}

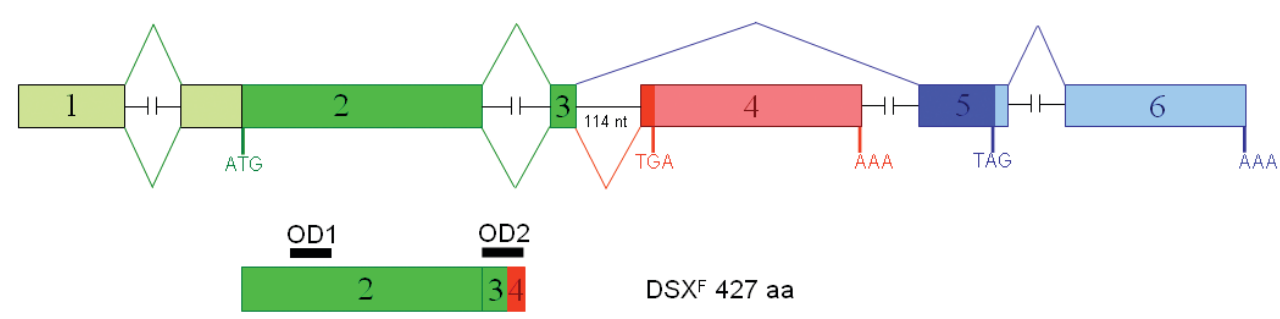

B

\section{C. capitata}

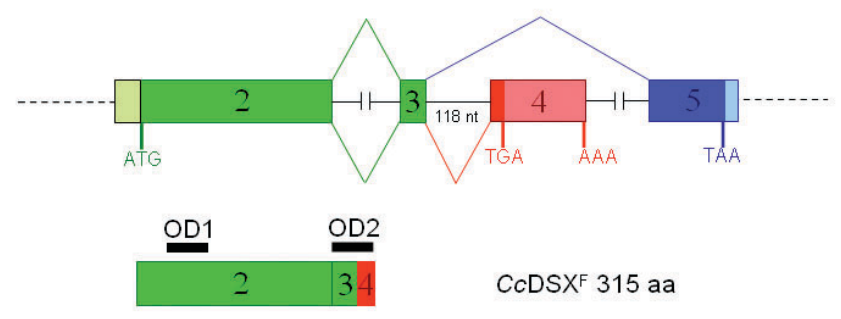

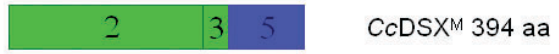

quence) and CcdsxP+ primer (from the Ccdsx 5'UTR - see supplemental data). A $1.1 \mathrm{~Kb}$ female-specific cDNA fragment (F2) was amplified by using the CcdsxP+ and the CcdsxF2000primers. The conceptual translation of the male and female amplicons indicates that they encode a polypeptide of 394 (CCDSX ${ }^{\mathrm{M}}$ acc. $\mathrm{n}^{\circ}$ : AF434935) and 315 amino acids (CCDSX acc. $n^{\circ}:$ AF435087), respectively.

An alignment of the two Ceratitissex-specific CcDSX isoforms led us to define respectively a 285 aa long common region, a 30 aa long female-specific region and a 109 aa long male-specific region. BLAST analysis showed that the two CcDSX isoforms are homologous to the corresponding sex-specific isoforms of many other dipteran species (the degree of identity ranges between 40-91\%), such as Bactrocera (Lagos et al., 2005, Shearman and Frommer, 1998) and Anastrepha species (Ruiz et al., 2007a, Ruiz et al., 2005), D. melanogaster (Burtis and Baker, 1989), Megaselia scalaris (Kuhn et al., 2000), Musca domestica (Hediger et al., 2004), the mosquitoes Anopheles gambiae (Scali et al., 2005) and Aedes aegypti(Mauro et al., in preparation). Figure 1 shows a multiple Clustal-W alignment of Ceratitis capitata DSX proteins with other dipteran DSX homologues. The $\mathrm{N}$-terminus of the Drosophila $\mathrm{DSX}^{\mathrm{F}}$ protein appears to be longer due to the presence of an about 100 aa region enriched in stretches of specific aminoacids, which is absent in the Ceratitis and other Tephritidae DSXF proteins. The most conserved regions are those corresponding to the Drosophila DSX protein OD1 (containing an atypical zinc finger DM domain) and OD2 domains (oligomerization domain that extends into the female-specific region), which serve as inter-

Fig. 2. Molecular organization of (A) the Ceratitis capitata dsx gene and its comparison with dsx of (B) D. melanogaster. Exons (boxes) and introns (lines - when broken indicate that the length of the corresponding intron is unknown) are not drawn to scale. The numbers inside the boxes indicate the number of the exon. The coding sequence of sex-specific transcripts and open reading frame (ORF) are shown in the figure. The beginning and the end of the ORF are indicated by ATG and TGA, TAG or TAA, respectively.

faces for protein-protein and protein-DNA interactions (An et al., 1996, Cho and Wensink, 1997). The Ccdsx sex-specific transcripts share a common region composed of two exons, but differ for the presence of a female- and a male-specific exons (Fig. 2). The exon/intron junctions depicted in the schematic in Fig. 2B have been unambiguously determined, comparing sexspecific cDNA and genomic sequences. Nucleotide sequence analysis of $C$. capitata $d s x$ led to identify sequence conservation of two cis regulatory elements described in the Drosophila dsx gene: 1) a weak polypyrimidine tract at the 3' acceptor splice site before the female-specific exon and 2) $d s x R E$ elements (putative Tra/Tra-2 binding sites) in the female-specific 3' untranslated region (Fig. 3).

The timing and the sex-specific pattern of expression of Ccdsx was studied by northern blot and RT-PCR analyses. Northern blot on total RNA, extracted from adult males and females, revealed that a prominent $3,6 \mathrm{~Kb}$ long transcript is present in males (Probe C, derived from 5' end of the Ov1 clone; Fig. 4A) while a single $3 \mathrm{~Kb}$ long transcript is produced in females (identified by Probe $C$ and Probe $F$, derived from 3 ' end of the Ov1 clone; Fig. 4A; the weaker signal by the probe $F$ is due to different exposure time). RT-PCR experiments were performed with an oligonucleotide mix containing one single forward (1400+) and 2 reverse primers (the male-specific M1130and the female-specific F2000-) on total RNA extracted from unfertilized eggs, embryos, larvae and pupae as well as from sexed adult flies. A single $0,6 \mathrm{~Kb}$ long cDNA product was observed in unfertilized eggs and embryonic stages (collected within 3-20h), which corresponds in size to the adult femalespecific splicing variant, while a doublet of 0,6 and $0,3 \mathrm{~Kb}$ was observed in larval and pupal stages, which correspond in size to the female- and male-specific products respectively observed in adult sexed flies (Fig. 4B). RT-PCR was performed also also on single larvae (data not shown) and on adult somatic tissues (male and female dissected heads), showing again the presence of the expected Ccdsx sex-specifically spliced products (data not shown).

The Ceratitis male-specific DSX isoform showed $51 \%$ identity and $58 \%$ similarity when compared to DmDSXM ${ }^{\mathrm{M}}$. To test whether the $\mathrm{CcDSX}^{\mathrm{M}}$ and $\mathrm{DmDSX}^{\mathrm{M}}$ proteins were functionally interchangeable, we examined the ability of the CcDSXM protein to induce masculinization of $D$. melanogaster $\mathrm{XX}$ flies by competing with the endogenous DmDSXF. We generated 20 Drosophila transgenic lines expressing a $C c d s X^{M}$ cDNA from the $h s p 70$ heat shock promoter (hsp70::CcDSXM). When raised at $25^{\circ} \mathrm{C}$, males and females, showed wild type anal and genital 


\section{D. melanogaster}

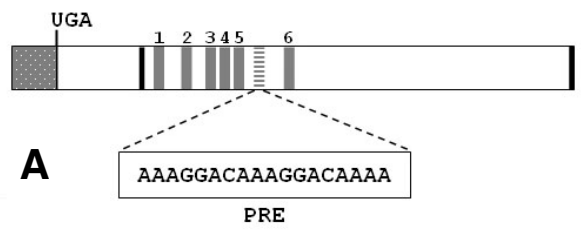

dsXRE-Dm1 TCTTCAATCAACA dsXRE-Dm2 TCTTCAATCAACA dSXRE-Dm3 TCTACAATCAACA dsXRE-Dm4 TCTTCAATCAACA dsXRE-Dm5 TCAACAATCAACA dsXRE-Dm6 TCAACGATCAACA

C. capitata

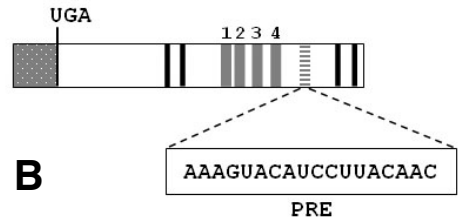
ds XRE-Cc1
ACT ACAATCAACA dsXRE-Cc2 TCTTCAATCAACA dsXRE-CC3 TCTGCAATCAACA dsXRE-CC4 TCAGCAAACAATC

Fig. 3 (Above). Distribution of Tra/Tra-2 binding sites (dsxRE elements) and Purine Rich Element (PRE) in the 3' untranslated region of $d s x$ female-specific exons. (A) D. melanogaster and (B) C. capitata. The dsxRE are marked in grey boxes. The PRE is marked as a lined box and the respective putative sequence is reported below. Putative polyadenylation signals are marked as black boxes and the stop codons are indicated. On the right of each diagram the dsxRE sequences present in the female-specific exon of the respective species are shown. The shading indicates identical nucleotides.

regions, and no evident reduction in viability or fertility. However, females of all transgenic lines showed full male-like pigmentation of the sixth tergite and variable pigmentation also of the fifth tergite (Fig. 5A - as in dsxM12 line). More severe adult phenotypes, similar to those described by Jursnich and Burtis (1993), were observed when transgenic animals were reared at $29^{\circ} \mathrm{C}$ and exposed to two daily heat shock regimens, from first instar larvae till adult stages: 1) transformation of legs bristles towards a sex-combs-like morphology (Fig. 5B), and larval/pupal lethality, with only a low number of adult escapers (approx $70-90 \%$ lethality). Masculinized females showed 2) full male-like pigmentation of the fifth tergite (Fig. $5 \mathrm{~A}-$ as in dsxM6 line), and 3) transformed genitalia, with reduction in the size of the vaginal plates and in the number of vaginal teeth (Fig. 5C). However, no pigmentation of dorsal spinules and ventral setae were observed in third-instar transgenic larvae. In two different transgenic lines, recovered after heat shock treatment, a few pseudomales (12 out of 70 survivors) showed strongly altered ( 7 flies) or even almost completely masculinized (5 flies) genitalia. Upon dissection these pseudomales displayed defective female or male germline tissues (Fig 5D). PCR-based analysis was used to asses the karyo-

A

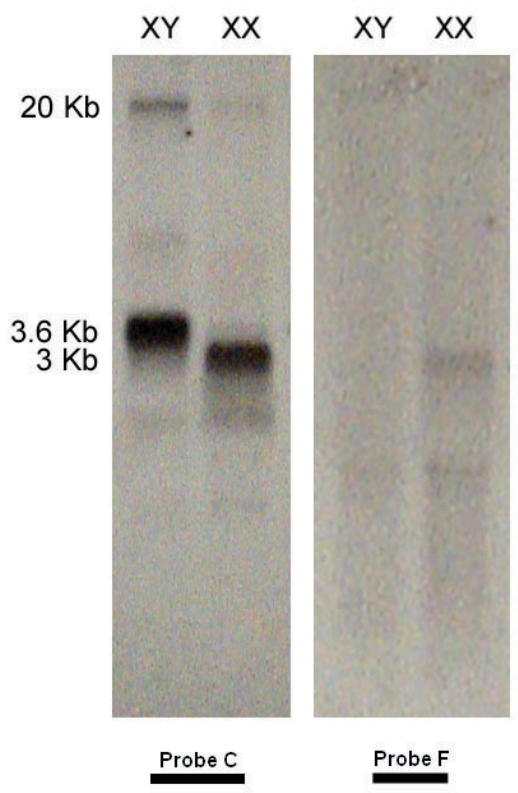

$\lambda \quad$ UE

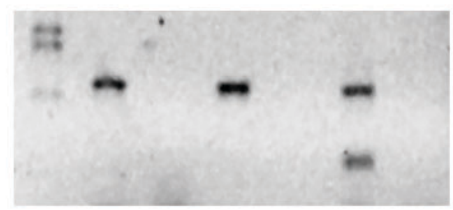

B

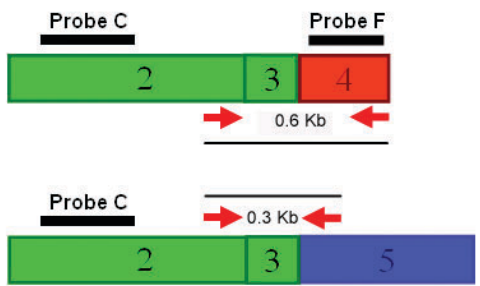

$\lambda \quad \mathrm{P} \quad \mathrm{XY} \quad \mathrm{XX}$

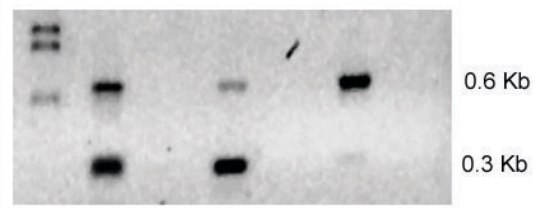

Ccds $x^{F}$ cDNA

Ccds $x^{\mathrm{M}} \mathrm{cDNA}$

Fig. 4. Timing of expression of the $\boldsymbol{C}$. capitata dsx gene. (A) Northern blots of total RNA from adult males (XY) and females (XX). Northerns were hybridized with two DNA probes obtained from the Ccdsx female cDNA: probe C, corresponding to the common region of the Ccdsx gene, and probe $F$, corresponding to female-specific region. (B) RT-PCR analyses on total RNA of unfertilized eggs (UE), embryos 3-20 h old (E), larvae (L), pupae (P), male $(X Y)$ and female $(X X)$ adults. At the bottom of $(B)$, the molecular organization of the corresponding $c D N A s$ and the localization of RT-PCR primers (red arrows) are shown. 
type of pseudomales from lines 2 and 11 using two $\mathrm{Y}$-specific primers and, as positive internal control, two primers specific for the autosomic Dmdsxgene (Fig. 5E). The lack of Y-specific amplification in pseudomales samples confirm their $X X$ karyotype.

\section{Discussion}

In this study we report the isolation and characterization of the Ceratitis capitata dsxgene ( $C c d s x$ ). As in Drosophila, Muscaand in two Tephritidae species, the Ccdsx gene is transcribed in males and females individuals, from early stages of development till adulthood, and its primary transcript undergoes sex-specific splicing, producing the female CcDSX ${ }^{\mathrm{F}}$ and male $\mathrm{CCDSX}^{\mathrm{M}}$ proteins. The presence of conserved Tra/Tra-2 binding sites within the female-specific exon of Ceratitis capitata $d s x$ gene further suggests that also in this species the $d s x$ female-specific splicing may be regulated by the gene products of Cctra and Cctra-2. Hence Ceratitis dsx female-specific splicing appears to be regulated by a conserved alternative splicing mechanism in which, as in Drosophila, during development the male-specific mode is the default state (default: absence of CcTRA), while the femalespecific mode is the regulated state, which requires the positive activity of the CcTRA/CcTRA-2 splicing complex, as also suggested by in vivo RNAi against Cctra and Cctra-2 (Pane et al., 2002; Salvemini et al., submitted). While in unfertilized eggs and $\mathrm{XX} / \mathrm{XY}$ embryos (3-20h) only the $C c d s x$ female-specific variant is amplified by RT-PCR, the male-specific variant seems to be present later on, from early larval stages. Hence we propose that Ceratitis male-sex differentiation is controlled by $\mathrm{Ccdsx}^{\mathrm{M}}$ as Dm $\mathrm{dsx}^{\mathrm{M}}$ in Drosophila, and it starts from larval developmental stages. It is presently thinkable that at embryonal stages sex determination of Ceratitis is set up by default in a female mode as suggested by the presence of maternal mRNAs corresponding to CcdsxF, but also CctraF and Cctra-2 (Salvemini et al., submitted) and that later on only in $\mathrm{XY}$ embryos Cctra and consequently Ccdsx switch the splicing pattern to the male mode, because of the action of the $\mathrm{Y}$-linked male determining factor, still to be

Fig. 5. Phenotypes of Drosophila hs::CcdsxM transgenic lines. (A) Abdominal pigmentation. Abdomens from wild type males $(X Y)$, females $(X X)$ and transgenic males display the characteristic dimorphic pigmentation patterns in the most posterior tergites, T5 and T6. In transgenic XX individuals male-like pigmentation of T5 and T6 tergites can be observed to a variable extent (lines ds $x M-12$ and $d s \times M-6$ ). (B) Bristle modification. Protothoracic leg of wild type male $(X Y)$, wild type female $(X X)$ and of transgenic female from line ds $x M-5$, without heat shock treatment (- h.s.; left) and after heath shock treatment (+ h.s.; right). After heat shock bristles of basitarsus region exhibited a slight bluntness and increased pigmentation. (C) External genitalia modification. XX transgenic female from ds $x$ M-2 line, recovered after heat shock treatment, display intersexual external genitalia: arrow*, male like anal plate; arrow**, male like lateral plate; arrow*** ${ }^{*}$, reduced vaginal plate. (D) Dissected genitalia of pseudomales from line $d s \times M-11$ and dsxM-2. We observed abnormal ovaries in flies from line 11 (indicated by arrow) and apparently normal testes in flies from line 2. (E) Y-specific PCR on carcasses of two pseudomales (from lines ds $x M-11$ and ds $x M-2$ ) and of a control male (M) and female (F) flies. The control amplification signal of $1 \mathrm{~Kb}$ is present in all samples while a Y-specific amplification signal of $0.5 \mathrm{~Kb}$ is observed only in XY male control sample. molecularly identified.

We presented data showing that the male-specific CcDSXM isoform induces a strong masculinization when expressed in Drosophila transgenic females. These results indicate that the $\mathrm{CcDSX}^{\mathrm{M}}$ protein can efficiently outweigh the endogenous DmDSX ${ }^{\mathrm{F}}$ protein causing a masculinization of the sexual dimorphic structures of the $X X$ transgenic flies. These results further show the biochemical capacity of the $\mathrm{CcDSX}^{\mathrm{M}}$ protein to interact with the
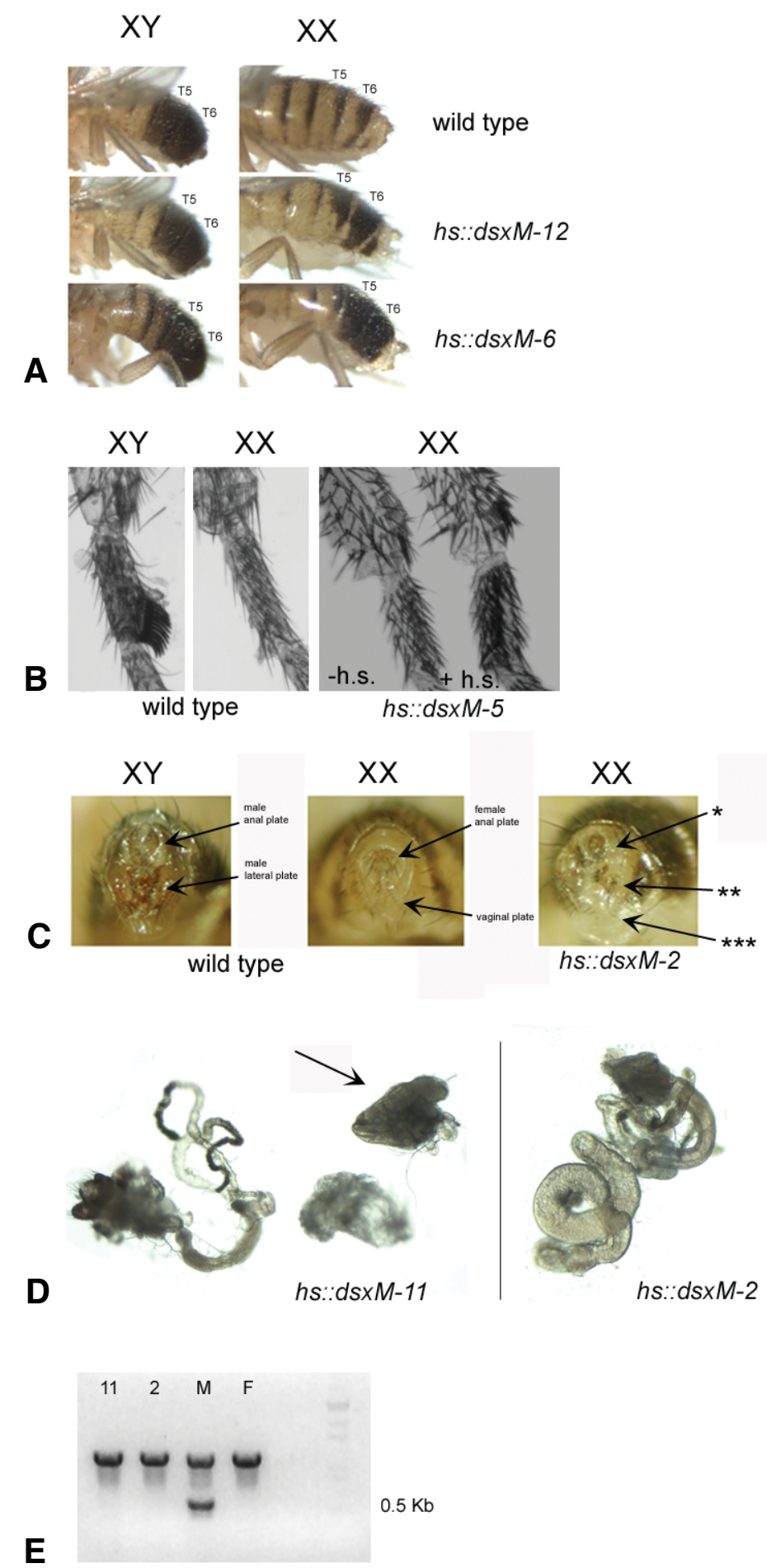
other regulatory partners of the Drosophila DSX protein and support the idea of its functional conservation in Ceratitis sex determination. Interestingly, in the case of trawhich is a functional conserved key female-determining gene in both Ceratitis and Drosophila, Pane et al. (2005) showed that CcTRA protein, although very weakly conserved in its sequence (18\% identity) and lenght (Cc 429 aa versus Dm 197 aa) is is able to efficiently feminize Drosophila XY transgenic flies. On the contrary in the case of Sxl which is a key female-determining gene in Drosophila but not in Ceratitis, Saccone et al. (1998) showed that the CcSXL protein, although very highly conserved is not able to efficiently feminize or kill (acting on dosage compensation) Drosophila XY transgenic flies. as expected in the case of conservation of its biochemical properties. These two previous studies in which an heterologous functional test for Ceratitis genes was successfully used, support the potential consistency of this "indirect" approach to evolutionary genetic functional conservation. Hence we suggest that not only the biochemical but also the developmental roles of the dsx ${ }^{\mathrm{M}}$ homologues are similar in both Ceratitis and Drosophila.

A similar experiment using Musca domestica DSX ${ }^{\mathrm{M}}$ transgene, driven by UAS/hsp70-GAL4 system (which usually permit higher expression levels with the respect of the simple hsp 70 fusion construct) in Drosophilalines, led only to male-like pigmentation of the posterior tergites (Hediger et al., 2004). The extent of pigmentation was much less pronounced than the one observed with $\mathrm{CcDSX}^{\mathrm{M}}$, possibly because the higher sequence similarity of CcDSXM to DmDSXM (58\% Cc/Dm versus 50\% Md/Dm), and the closer phylogenetic relationship of Ceratitis to Drosophila (both belong to Acalyptratae), than to Musca (Calyptratae).

It has been shown that the sex of Drosophila germ line requires cell-autonomous and inductive signals from the gonadal soma (Hempel and Oliver, 2007, Nothiger et al., 1989, SteinmannZwicky et al., 1989). The underdeveloped gonads of $\mathrm{XX}$ pseudomales expressing the $\mathrm{CcDSX}{ }^{\mathrm{M}}$ protein cannot be explained by the expression of this protein within the $X X$ germ cells since the ds $x$ gene is not cell-autonomously required for oogenesis: $X X$ cells either lacking $d s x$ function or expressing the DSXM protein form normal oocytes when transplanted into a female embryo (Schupbach, 1982). Rather, the defective gonads are likely the consequence of masculinisation of the female gonadal soma caused by the CcDSX ${ }^{M}$ protein so that no match exists between the cell-autonomous female signal of $X X$ germ cells and the masculinised signal from their surrounding gonadal soma. It is hence conceivable that the transgene in some Drosophila transgenic lines can express $\mathrm{CCDSX}^{\mathrm{M}}$ at a level such that a strong masculinizing somatic signal is sent to the $X X$ germ line cells, inducing them to become spermatogenetic.

In conclusion, Ceratitis capitata sexual differentiation seems to be controlled as in Drosophila by the binary switch gene $d s x$, encoding conserved sex-specific transcriptional factors. It will be of interest in future to identify the main gene targets of DSX in both species to evaluate the stability and the divergence of the downstream branching genetic networks which control the development of the sexual dimorphic traits.

\section{Materials and Methods}

\section{Cloning of Ccdsx gene}

The screening of C. capitatacDNA libraries was performed using a 300 bp PCR fragment amplified from Drosophila genomic DNA using primers for the female-specific region (Dmdsx2251+ and Dm dsx2541-). Hybridization and identification of positive clones were performed using standard protocols described in Maniatis etal. (1982). All PCR and RT-PCR products were sub-cloned in pUC18 cloning vector (Promega).

\section{Northern blots and RT-PCR}

Northern blots and hybridizations were performed according to standard protocols (Maniatis et al., 1982). For RT-PCR analyses two micrograms of total RNA from each developmental stage were reverse transcribed with the Superscript II RNase H - reverse transcriptase (Invitrogen) using oligo dT primers and following the manufacturer's instructions. $1 / 20 \mathrm{v} / \mathrm{v}$ of the synthesised cDNA was amplified by PCR. RT-PCR products were analyzed by agarose gel electrophoresis. The primers used are: CcdsxC 1400+ located in Ccdsx common exon 3, CcdsxM 1130- located in Ccdsxmale-specific exon 5 and CcdsxF 2000-located in Ccdsx female-specific exon 4. RT-PCR products were gel-purified, cloned using the pGEM-T Easy Vector Kit (Promega) and sequenced with Big Dye ${ }^{\circledR}$ Terminator v1.1 Sequencing Kit (Applied Biosystem).

\section{Generation of CcDSX ${ }^{\mathrm{M}}$ Drosophila transgenic lines}

Germline transformation experiments were performed as described by Rubin and Spradling (Rubin and Spradling, 1982). Preblastoderm embryos of $D$. melanogasterwere injected with $500 \mathrm{ng} / \mu$ l of pCaSpeR-hs$C c d s x^{\mathrm{M}}$-act vector and $150 \mathrm{ng} / \mu \mathrm{l}$ of the P-element $\Delta 2-3$ helper vector and 20 transgenic lines were produced. To induce the expression of the $C c d s x^{\mathrm{M}}$ cDNA from the Hsp70 promoter, flies from each line were reared at $29^{\circ} \mathrm{C}$ and exposed twice a day to heat-shock regimen at $37^{\circ} \mathrm{C}$ for $1 \mathrm{hr}$, from embryonic stages until adulthood.

\section{Karyotyping of Drosophila pseudo-females}

Genomic DNA of pseudo-females from transgenic lines 2 and 11 was extracted using the DrosophilaDNA/RNA Isolation protocol developed by Andres and Thummel (Andres and Thummel, 1994). Y-specific PCR was performed for each line on $50 \mathrm{ng}$ of the extracted genomic DNA with 1 unit of Taq Polymerase (Amersham Pharmacia) according to the manufacturer's directions in the presence of the specific primers for $D m C C Y$ gene and of Dmdsxgene as internal control (CCY+, CCY-, DMF and DF primers).

\section{Sequences of primers utilized in this paper \\ Dmdsx2251+ 5'-AGCCATTTGCCGATCTC-3' \\ Dmdsx2541- 5'-TCATCCACATTGCCGCG-3' \\ BtdsxM 5'- TGTTGCTGTTACGTAGCTGC-3' \\ CcdsxP+ 5'-ATAGGCATCGTAGCTGTTCT-3' \\ CcdsxC 1400+ 5'-GGCATCAAGGCGTATAGAAGA-3' \\ CcdsxM 1130- 5'-CTGGTGGTGACATCGTATCG-3' \\ CcdsxF 2000- 5'-ACGACGGCATGACCTTTAAC-3' \\ CCY+ 5'-CACTGGAGTGGTTCCTGC-3' \\ CCY- 5'-ATTGCTCCCTACAATCTTCC-3' \\ DMF 5'-CCGCTATCCTTGGGAGCT-3' \\ DF 5'-TTGAGATTGGCTTGTATGCC-3'}

\section{Acknowledgements}

We thank Leonard Rabinow and Lucas Sanchez for critical reading of the manuscript and for helpful suggestions. This work was supported by grants from the Ministero della Ricerca Scientifica e Tecnologica (PRIN 2006) to C. P.

\section{References}

AMREIN, H., GORMAN, M. and NOTHIGER, R. (1988). The sex-determining gene tra-2 of Drosophila encodes a putative RNA binding protein. Ce//55: 1025-35.

AN, W., CHO, S., ISHII, H. and WENSINK, P.C. (1996). Sex-specific and non-sexspecific oligomerization domains in both of the doublesex transcription factors from Drosophila melanogaster. Mol Cel/ Bio/16: 3106-11. 
ANDRES, A.J. and THUMMEL, C.S. (1994). Methods for quantitative analysis of transcription in larvae and prepupae. Methods Cell Bio/44: 565-73.

BAKER, B.S. and WOLFNER, M.F. (1988). A molecular analysis of doublesex, a bifunctional gene that controls both male and female sexual differentiation in Drosophila melanogaster. Genes Dev 2: 477-89.

BURGHARDT, G., HEDIGER, M., SIEGENTHALER, C., MOSER, M., DUBENDORFER, A. and BOPP, D. (2005). The transformer2 gene in Musca domestica is required for selecting and maintaining the female pathway of development. Dev Genes Evo/215: 165-76.

BURTIS, K.C. and BAKER, B.S. (1989). Drosophila doublesex gene controls somatic sexual differentiation by producing alternatively spliced mRNAs encoding related sex-specific polypeptides. Cel/56: 997-1010.

CHO, S. and WENSINK, P.C. (1997). DNA binding by the male and female doublesex proteins of Drosophila melanogaster. J Biol Chem 272: 3185-9.

CLINE, T.W. (1984). Autoregulatory functioning of a Drosophila gene product that establish es and maintains the sexually determined state. Genetics 107: 23177.

ERICKSON, J.W. and QUINTERO, J.J. (2007). Indirect effects of ploidy suggest x chromosome dose, not the x:a ratio, signals sex in Drosophila. PLOS Bio/5: e332.

GRAHAM, P., PENN, J.K. and SCHEDL, P. (2003). Masters change, slaves remain. Bioessays 25: 1-4.

HEDIGER, M., BURGHARDT, G., SIEGENTHALER, C., BUSER, N., HILFIKERKLEINER, D., DUBENDORFER, A. and BOPP, D. (2004). Sex determination in Drosophila melanogaster and Musca domestica converges at the level of the terminal regulator doublesex. Dev Genes Evo/214: 29-42.

HEMPEL, L.U. and OLIVER, B. (2007). Sex-specific DoublesexM expression in subsets of Drosophila somatic gonad cells. BMC Dev Biol7: 113.

HOSHIJIMA, K., INOUE, K., HIGUCHI, I., SAKAMOTO, H. and SHIMURA, Y. (1991). Control of doublesex alternative splicing by transformer and transformer-2 in Drosophila. Science 252: 833-6.

JURSNICH, V.A. and BURTIS, K.C. (1993). A positive role in differentiation for the male doublesex protein of Drosophila. Dev Biol155: 235-49.

KEISMAN, E.L. and BAKER, B.S. (2001). The Drosophila sex determination hierarchy modulates wingless and decapentaplegic signaling to deploy dachshund sex-specifically in the genital imaginal disc. Development 128: 1643-56.

KOPP, A., DUNCAN, I., GODT, D. and CARROLL, S.B. (2000). Genetic control and evolution of sexually dimorphic characters in Drosophila. Nature 408: 553-9.

KUHN, S., SIEVERT, V. and TRAUT, W. (2000). The sex-determining gene doublesex in the fly Megaselia scalaris: conserved structure and sex-specific splicing. Genome 43: 1011-20.

LAGOS, D., KOUKIDOU, M., SAVAKIS, C. and KOMITOPOULOU, K. (2007). The transformer gene in Bactrocera oleae: the genetic switch that determines its sex fate. Insect Mol Biol 16: 221-30.

LAGOS, D., RUIZ, M.F., SANCHEZ, L. and KOMITOPOULOU, K. (2005). Isolation and characterization of the Bactrocera oleae genes orthologous to the sex determining Sex-lethal and doublesex genes of Drosophila melanogaster Gene 348: 111-21.

MANIATIS, T., SAMBROOK, J. and FRITSCH, E. (1982). Molecular Cloning - A Laboratory Manual. CSH Press.

NAGOSHI, R.N., MCKEOWN, M., BURTIS, K.C., BELOTE, J.M. and BAKER, B.S (1988). The control of alternative splicing at genes regulating sexual differentiation in D. melanogaster. Cel/53: 229-36.

NOTHIGER, R., JONGLEZ, M., LEUTHOLD, M., MEIER-GERSCHWILER, P. and WEBER, T. (1989). Sex determination in the germ line of Drosophila depends on genetic signals and inductive somatic factors. Development 107: 505-18.

PANE, A., SALVEMINI, M., DELLI BOVI, P., POLITO, C. and SACCONE, G. (2002) The transformer gene in Ceratitis capitata provides a genetic basis for selecting and remembering the sexual fate. Development 129: 3715-25.

PANE, A., DE SIMONE, A., SACCONE, G. and POLITO, C. (2005). Evolutionary conservation of Ceratitis capitata transformer gene function. Genetics.171: 615624.

RUBIN, G.M. and SPRADLING, A.C. (1982). Genetic transformation of Drosophila with transposable element vectors. Science 218: 348-53.

RUIZ, M.F., EIRIN-LOPEZ, J.M., STEFANI, R.N., PERONDINI, A.L., SELIVON, D. and SANCHEZ, L. (2007a). The gene doublesex of Anastrepha fruit flies (Diptera, Tephritidae) and its evolution in insects. Dev Genes Evo/217: 725-31.

RUIZ, M.F., MILANO, A., SALVEMINI, M., EIRIN-LOPEZ, J.M., PERONDINI, A.L., SELIVON, D., POLITO, C., SACCONE, G. and SANCHEZ, L. (2007b). The gene transformer of anastrepha fruit flies (Diptera, tephritidae) and its evolution in insects. PLOS ONE2: e1239.

RUIZ, M.F., STEFANI, R.N., MASCARENHAS, R.O., PERONDINI, A.L., SELIVON, D. and SANCHEZ, L. (2005). The gene doublesex of the fruit fly Anastrepha obliqua (Diptera, Tephritidae). Genetics 171: 849-54.

SACCONE, G., PEluso, I., ARTIACO, D., GIORDANO, E., BOPP, D. and POLITO, L.C. (1998) The Ceratitis capitata homologue of the Drosophila sexdetermining gene sex-lethal is structurally conserved, but not sex-specifically regulated. Development 125: 1495-1500.

SANCHEZ, L. and GUERRERO, I. (2001). The development of the Drosophila genital disc. Bioessays 23: 698-707.

SCALI, C., CATTERUCCIA, F., LI, Q. and CRISANTI, A. (2005). Identification of sex-specific transcripts of the Anopheles gambiae doublesex gene. J Exp Biol 208: 3701-9.

SCHUPBACH, T. (1982). Autosomal mutations that interfere with sex determination in somatic cells of Drosophila have no direct effect on the germline. Dev Biol 89: 117-27.

SHEARMAN, D.C. and FROMMER, M. (1998). The Bactrocera tryoni homologue of the Drosophila melanogaster sex-determination gene doublesex. Insect Mol Biol7: 355-66.

STEINMANN-ZWICKY, M., SCHMID, H. and NOTHIGER, R. (1989). Cell-autonomous and inductive signals can determine the sex of the germ line of drosophila by regulating the gene Sxl. Cel/57: 157-66. 


\section{Further Related Reading, published previously in the Int. J. Dev. Biol.}

See our recent Special Issue Fertilization, in honor of David L. Garbers and edited by Paul M. Wassarman and Victor D. Vacquier at: http://www.ijdb.ehu.es/web/contents.php?vol=52\&issue=5-6

Sex-determining mechanisms in insects

2006 ISI **Impact Factor $=3.577^{* *}$

Lucas Sánchez

Int. J. Dev. Biol. 52: 837 - 856 (2008)

Stage-specific regulation of programmed cell death during oogenesis of the medfly Ceratitis capitata (Diptera, Tephritidae)

Athanassios D. Velentzas, Ioannis P. Nezis, Dimitrios J. Stravopodis, Issidora S. Papassideri and Lukas $\mathrm{H}$. Margaritis

Int. J. Dev. Biol. (2007) 51: 57-66

mgm 1, the earliest sex-specific germline marker in Drosophila, reflects expression of the gene esg in male stem cells.

Adrian Streit, Luca Bernasconi, Pavel Sergeev, Alex Cruz and Monica SteinmannZwicky

Int. J. Dev. Biol. (2002) 46: 159-166

Musca domestica, a window on the evolution of sex-determining mechanisms in insects.

Andreas Dübendorfer, Monika Hediger, Géza Burghardt and Daniel Bopp

Int. J. Dev. Biol. (2002) 46: 75-79

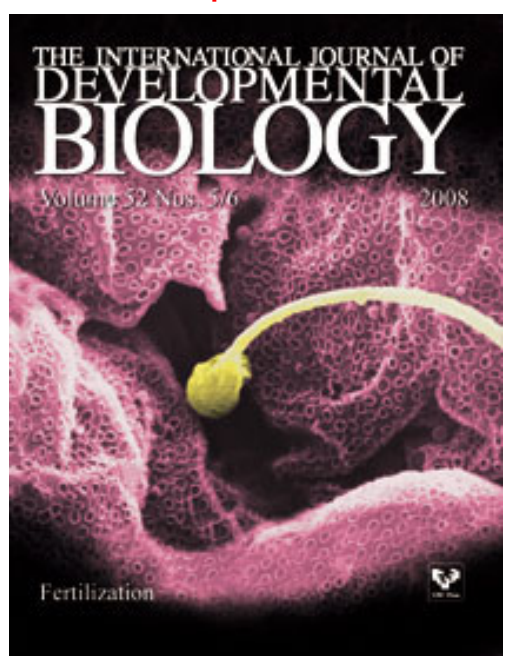

